\title{
Data Analytics in Master Cam Setup Sheet for Improved Manufacturing
}

\author{
V. V. Shukla, P. V. Sawalakhe, J. A. Shaaikh, M. G. Trivedi, N. P. Gudadhe
}

\begin{abstract}
The paper focusses on providing the awareness of smart manufacturing utilizing simulation through modelling in order to facilitate data analytics. Data analytics related to manufacturing will prove its noteworthy benefits to processes involved in industry. Models simulated for manufacturing techniques can be utilized to facilitate data analytics in numerous ways. The provision offered in Mastercam offer programmers to support models simulated to various sectors like logistics, management, transportation, health systems and manufacturing making simulation tool a popular one. It provides three types of stages of process knowledge namely a machine level, a shop level and a universal level. The universal level is related to the knowledge of a process independent of machine or individual shop which facilitates the process. Furthermore, analogous process knowledge like shape capabilities of machining and manufacturing processes offers to progress processes involved in manufacturing through Mastercam.
\end{abstract}

Keywords: CAM, Customization of setup sheet, Data Analytics, Mastercam, , process \& energy optimization;

\section{INTRODUCTION}

Agile production needs an evaluation and management apparatus for changing operations planning, production, configuration and manufacturing system development. Outdated static production planning procedures are insufficient; Planners in the field of production requires dynamic and precise prototypes of production, means a simulation model which aims at using data related to real shop floor and production network. Mastercam is a software, dedicated to provide state-of-the-art tools for CAD/CAM manufacturing markets. Mastercam, helps machinists to design computer generated parts on a desktop computer screen and guide the manufacture of parts.

Revised Manuscript Received on February 05, 2020.

* Correspondence Author

Dr. V. V. Shukla, Associate Professor, Department of Mechanical Engineering Shri Ramdeobaba College of Engineering and Management, Nagpur, M.S., India PH-9822277318. E-mail: shuklavv2@rknec.edu

Dr. P. V. Sawalakhe, Assistant Professor, Department of Mechanical Engineering Shri Ramdeobaba College of Engineering and Management, Nagpur, M.S., India PH-90493747868. E-mail: sawalakhepv@rknec.edu

Jahier Abbas Shaaikh, Lecturer, Department of Mechanical Engineering, Debre Tabor University, Ethiopia

M. G. Trivedi, Assistant Professor, Department of Mechanical Engineering, Shri Ramdeobaba College of Engineering and Management (RCOEM), Nagpur, India.

N. P. Gudadhe, Assistant Professor, Department of Mechanical Engineering, Shri Ramdeobaba College of Engineering and Management (RCOEM), Nagpur, India.

(C) The Authors. Published by Blue Eyes Intelligence Engineering and Sciences Publication (BEIESP). This is an open access article under the CC BY-NC-ND license (http://creativecommons.org/licenses/by-nc-nd/4.0/)
Setup sheet is a technique to present all the data used for machining in a specified manner. The setup sheet can be developed manually or it can be generated on software. Setup sheets are generated only through CAM software so it is important to provide any client with a formatted setup sheet as per requirement. A generic setup sheet would have following parameters in it: Operations list, Tool List, Tool materials with its cutting parameters, Instruction or Remarks for manufacturing, Offsets used for machining, Real time data values, Estimated time for job completion Each company in the market having any kind of manufacturing setup uses a setup sheet in the production line.

\section{LITERATURE SURVEY}

Guilabert(2003) discussed an effort made to cultivate a standardized scaffold for examining customers openness in favoring tailored products, a scale containing six main dimensions was established. The outcome of the developed sub-process is the solution space which contains the list of product replacements that can be constructed by the mass customizer. [2]

Hart (2004), evaluates that customers are in need of customized products and uses the idea of "customer customization sensitivity". This concept depends on two criteria's like level of customer sacrifice and the uniqueness of customers. [3]

Chang et al. (2006), discussed about the knowledge of resources related to manufacturing for planning of process. It also states the geometric tolerances and dimensions resulted from different processes. Finally, it throws light on parameters related to machining like speed of a cutter, feeds and metal removal rate related to process [4].

Xu HM el al. (2007) \& (2008) Recent study related to significant changes in standards of manufacturing which is now transferred from conventional manufacturing to a agile manufacturing. This led to destroy of competition between the products due to shortening of product lifecycles globally. For gaining agility, pro-activeness, robustness and responsiveness plays a major role. [5,6,7].

Adhithan et al. (2009) has presented Mastercam. It is 2D CAM system having CAD tools which enables user to design Computer generated parts on a desktop and also guides CNC tools for manufacturing of parts.

Eventually 2D CAM system was modified to 3D system as per need of time [1].

Groover et al. (2009) states the information about the newly released Mastercam X (10), It provides many modifications over the earlier version and gained a feel of true windows application. 


\section{Data Analytics in Master Cam Setup Sheet for Improved Manufacturing}

It supports many choices of machines having different functions and provide add-ins for 5-axis machining, solid modelling and 4-axis machining [27].

Summers et al. (2010)Team developed advancements in setup sheet functionality of Mastercam software. Generic layout of setup sheets were developed with default usage for all customers using their software [13].

\section{PROCEDURE FOR SETUP SHEET CUSTOMIZATION}

There is lot of research work being done and proposed different systematic approaches to manage the customized set up sheet. General set of active elements for a given setup sheet in any CAM software is discussed in the below diagram.

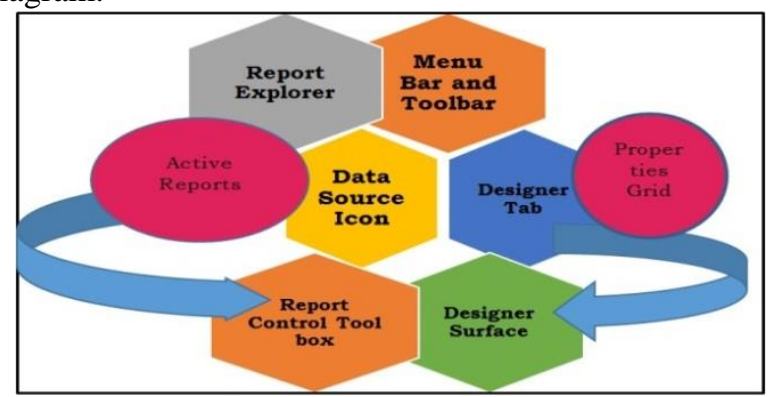

Figure 1 gives details of different active elements present in setup sheet.[15]

To customize any given setup sheet, prior need to understand the relationship between various elements of the setup sheet. The report explorer and toolbar are used to collect data and then converted into active reports and then customized so as to get output results. Customization is a technique to modify any given thing for a particular application. It becomes a narrow approach to the solution as in customization due to limits. In this, machining time is reduced and increases the tool life to sustain the cutting process using full flute length, and which is used for accurate results and time-saving constraints at every aspect of the cutting process. Every possible combination of the setup sheet can be made accessible to the customer if they are customized. For example, some may need only tool list, some may need an operation list, some may need images with tool parameters etc. In Mastercam software, only get the default setup sheet and it has to be used as it. If such a sheet has to be customized then for that we have to use Active report designer which is add on type in Mastercam. This ARD was introduced in Mastercam from version X5. Before this, it was not possible for anyone to modify any kind of setup sheet in Mastercam. Default locations of such developed setup sheets are in “.xml” format and are saved in XML folder.

\section{A. SETUP SHEET FLOW CHART}

Before customizing any specific setup sheet it is important to collect filtered data from specific industry. Figure 2 represents the functional flow chart of Set up file preparation. It is useful for the initial process developing of setup sheets. Once the customer is ready with all data or documentation then as per the algorithm of flow chart, the requirement is designed and segregated in the required specific setup sheet. A separate setup sheet can be generated for the company, with the need to design the specific sheets as per stage and requirement, with this software, which can generate tool path for the same. Then generate setup sheet with help of coding for our required parameters. Verification of such sheet is done by using ADR, specifically in case of Mastercam software. After gaining the verified result, document the setup sheet as per format of client.

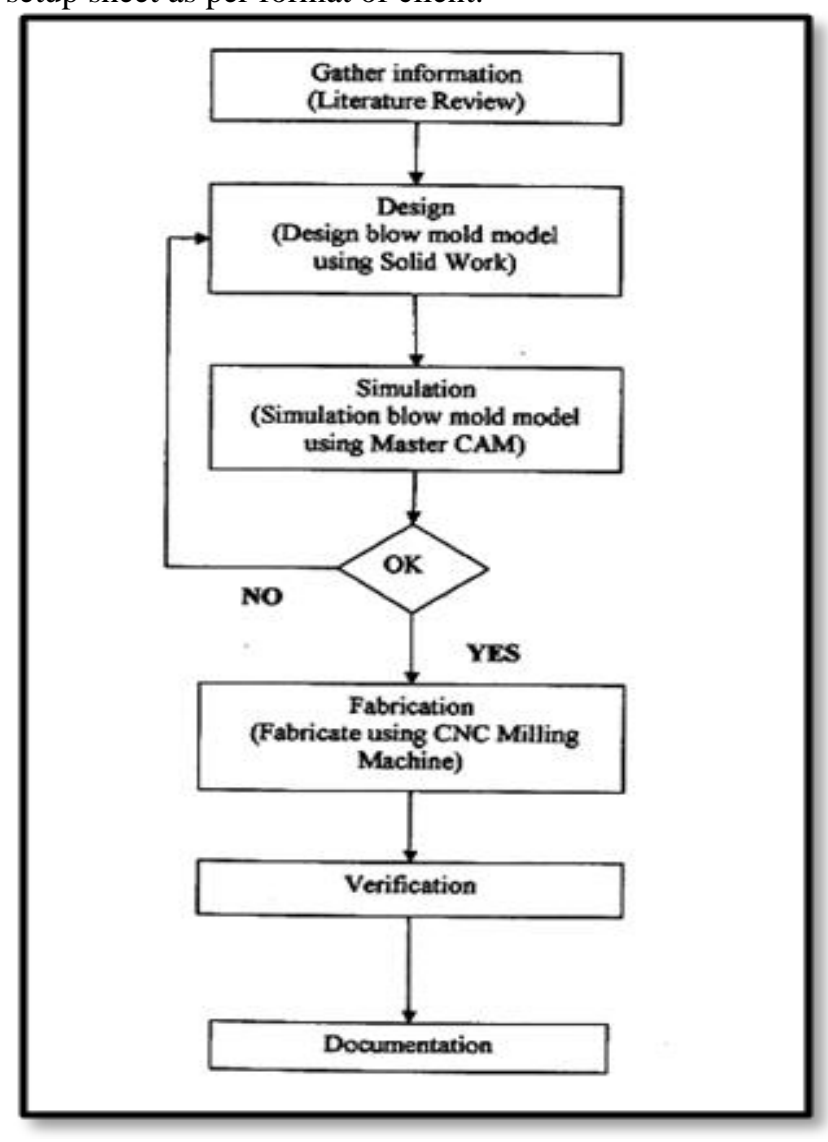

Figure 2 Flow Chart Descriptions for Setup Sheet [15]

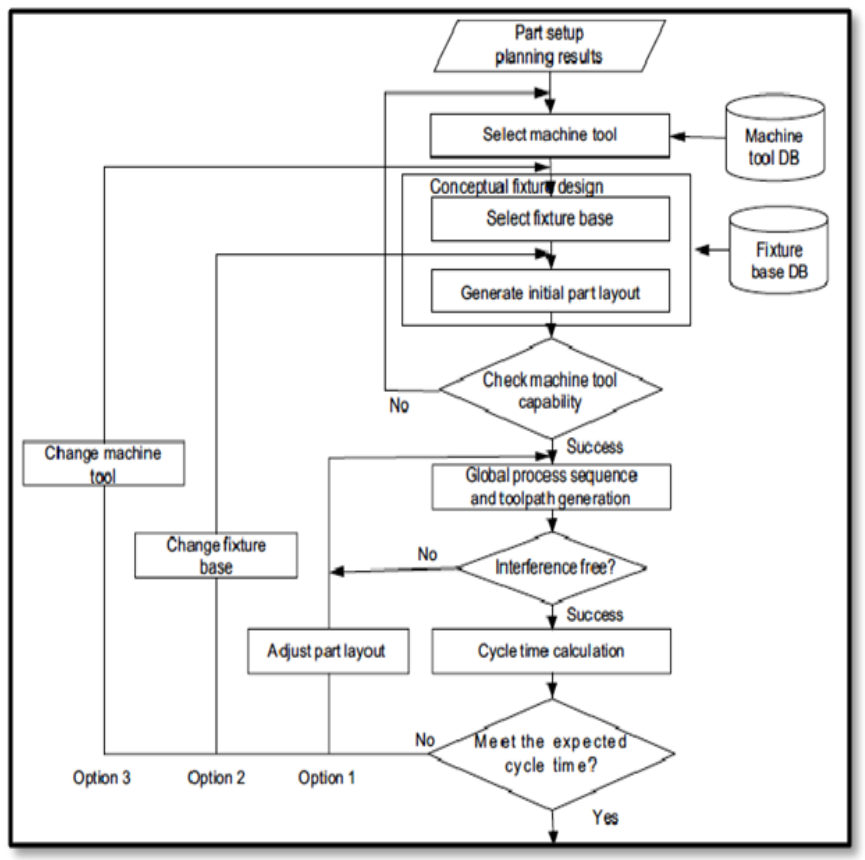

Figure 3 Overall Manufacturing Time for a Component [15]

Published By:

Blue Eyes Intelligence Engineering

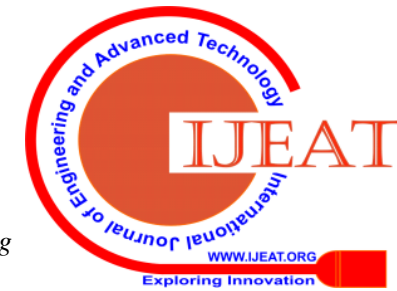


CAM can be controlled by controlling the parameters like, time for cutting, overall time required for manufacturing. Most of the cycle time is consumed by none cutting time including machine table index time, cutter changing time and cutter rapid traverse time. In case of mass production usage of multi-part fixtures reduce cycle time and improve productivity.

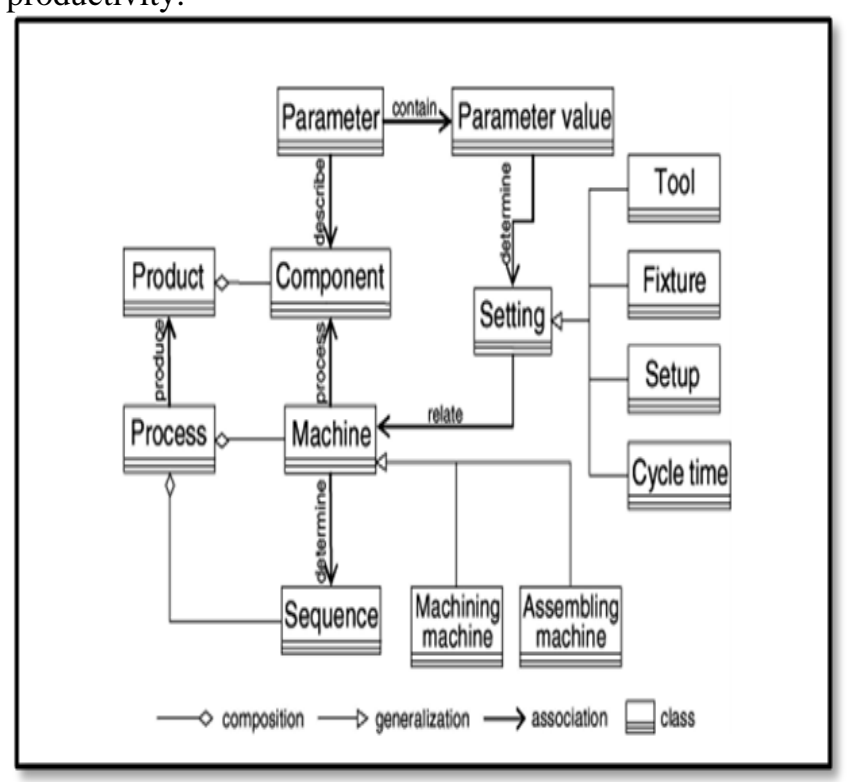

Figure 4. Data Process for Setup Sheets [15]

Figure 4 shows the correlations among the various process data. In the figure, the set of parameter values associate process data to product data, and thus depicts the interrelation of design and production. For any changes in design, the corresponding variations in production can be specified according to these interrelationships. Meanwhile, the identification of appropriate machines, machine settings, and operations sequences can also be accomplished based on these parameter values.

\section{RESULT}

Following setup sheets are designed by taking different inputs and different conditions. ARD allows integrating, all various parameters into one sheet. This sheet is called the Main report sheet. Such a sheet has extension ".rpx" and could be saved in "pdf" or "rdf" format only. The main sheet can contain various sub sheets together to form one report. For all the processes first, generate the sub reports and then link its .xml file to the main report and regenerate it. At the time of customization, each time at the development of this sheet also generate the date and title by default as per the actual day of the performance, and other parameters are the variables and can be modified as and when required by the user. All these results are taken for various scenario and parameters, which company requires frequently for any part or components machining. These setup sheets can be used by both small scale industrial and large scale industries as per their machining requirements.

\section{Setup Sheet 1: Raw Material}

First Setup sheet contains 2D image of job setup for reference and basic details required for company no. 1 . Here only block size machine type, material used, etc. are customized. Such type of setup sheets are generally used in industries where only 2D operations are being carried out. Parameters to be obtained as per client requirement are as follows: Date, Machine type and controller name, 3D view for finished component along with the stock size / raw material size and material used for cutting.

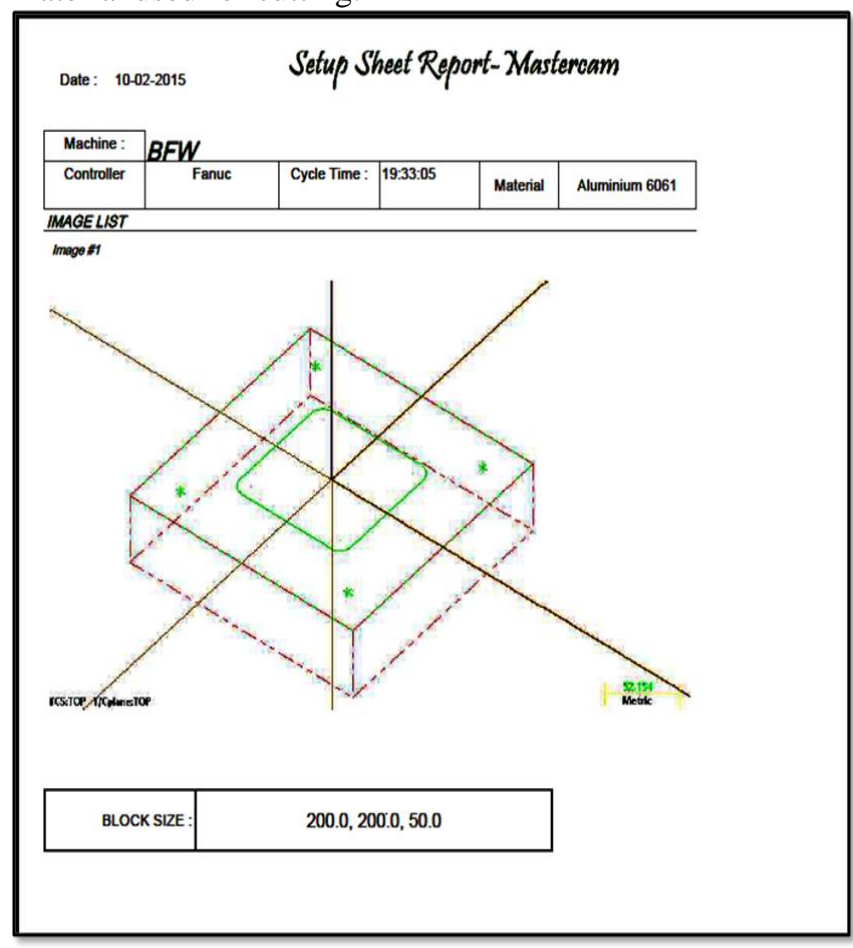

Figure 5 Setup Sheet for Customer 01

\section{Setup Sheet 2: Operational List}

Second Setup sheet contains operation descriptions for a particular job. It does not include any image. Only inputs parameters provided by company. Such type of setup sheet is used in industries where sequence of operations is important.

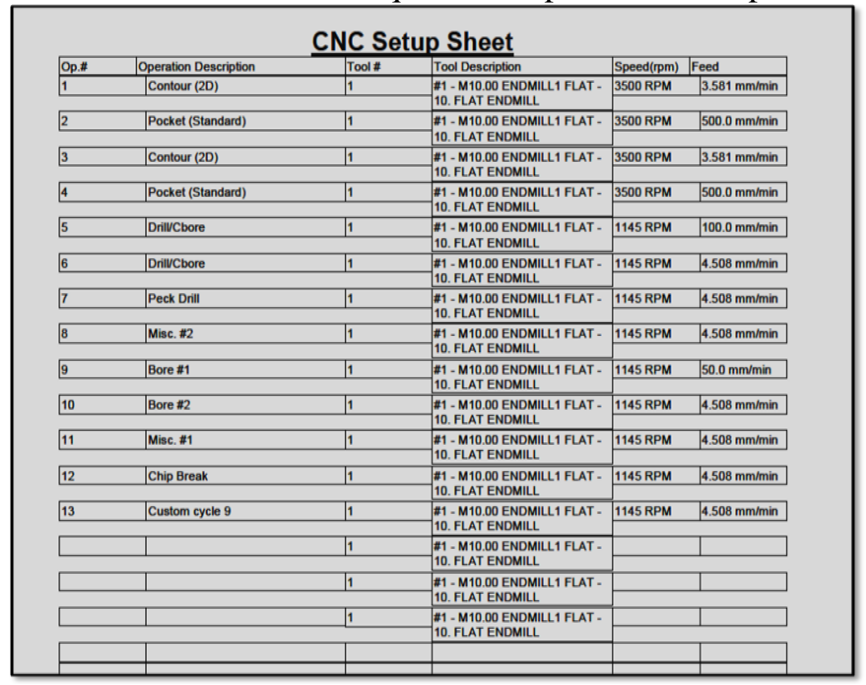

Figure 6 Setup Sheet for Customer 02 


\section{Data Analytics in Master Cam Setup Sheet for Improved Manufacturing}

\section{Setup Sheet 3: Small Scale Industry}

Third setup sheet contains tool details, feed, speed etc. Such type of setup sheet is used in small scale industries where operator has to know only specific detail related to machining.

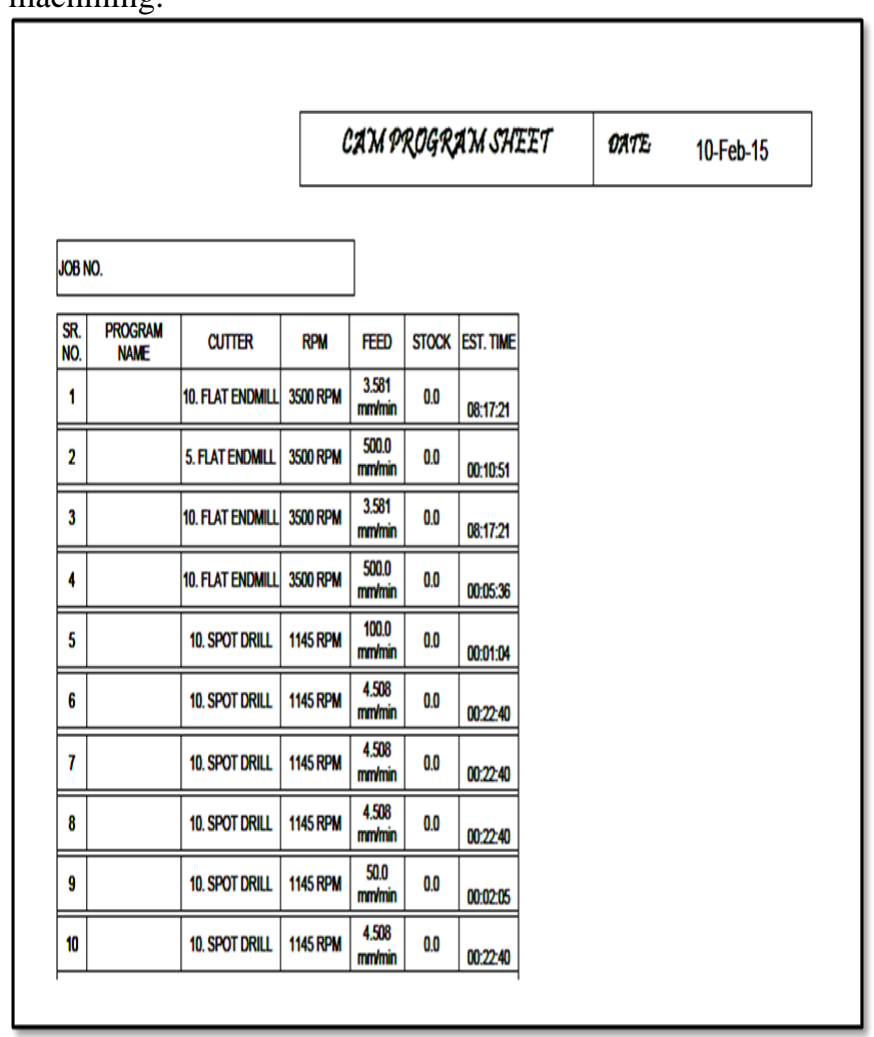

Figure 7 Setup Sheet for Customer 03

\section{Setup Sheet 4: Individual List Sheet}

Fourth Setup sheet contains customization done for each operation. If individual operations are handled by various operators in big industries then there is no need to give each one of them all operation lists.

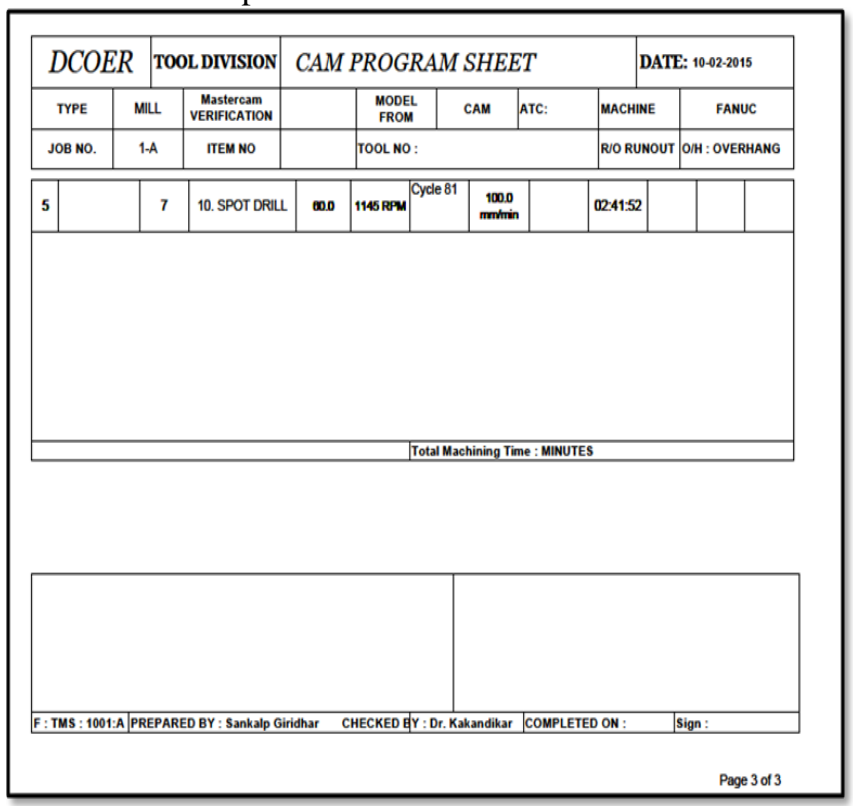

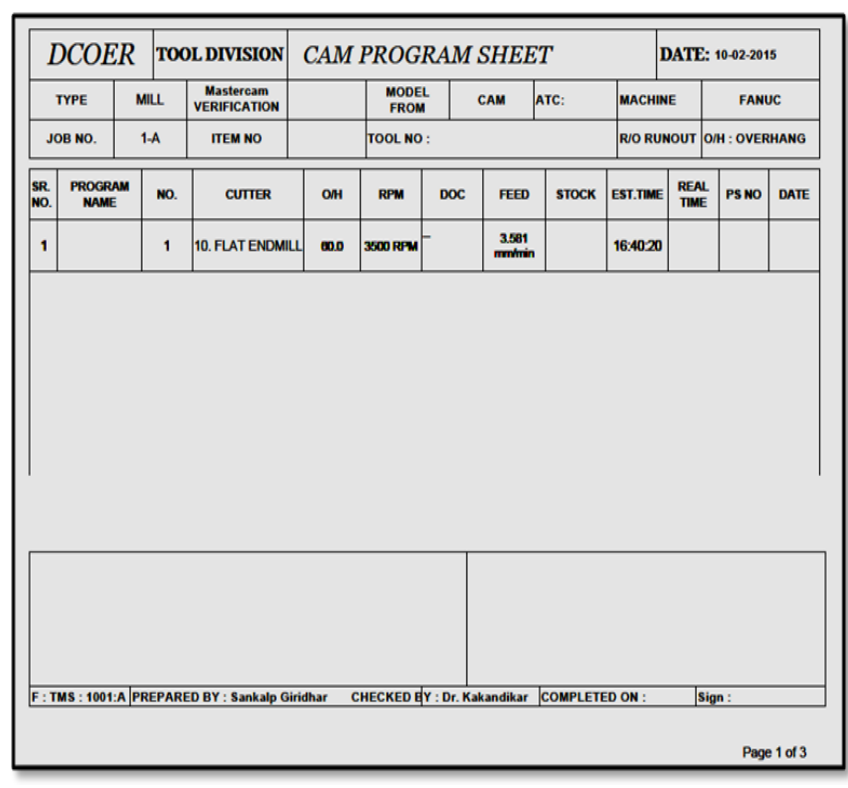

Figure 8 Setup Sheet for Customer 04

Setup Sheet 5: 3d Modelling

Fifth Setup sheet contains 3D modelling job setup.

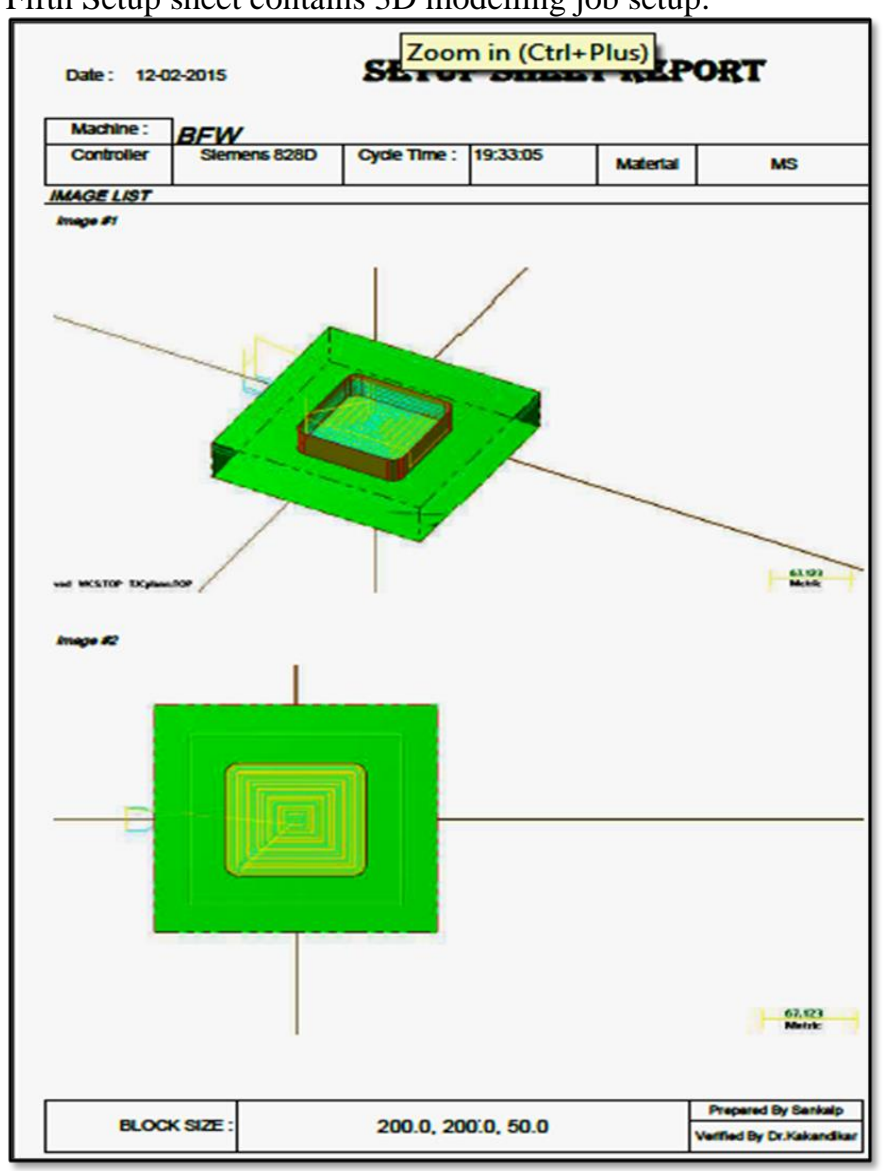

Figure 9 Setup Sheet for Customer 05

Setup Sheet 6: Parameters as Per Customer Requirement Sixth Setup sheet contains CAM program sheet along with data provided by company. This data includes only some parameters and real time and estimated time are compared to get final efficiency of machining.Parameters to be obtained as per client requirement are as follows:

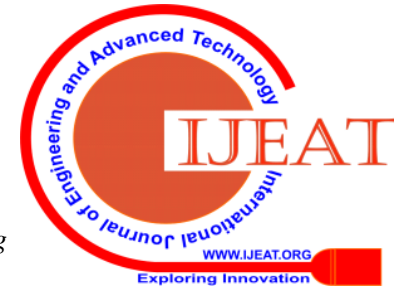


Cutting parameters, machine details, remarks for machining, comments for verification.

Part A

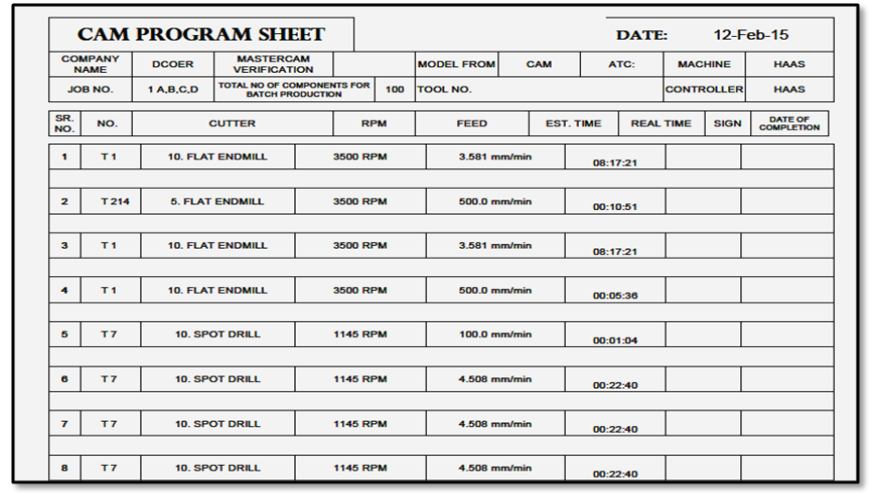

Part B

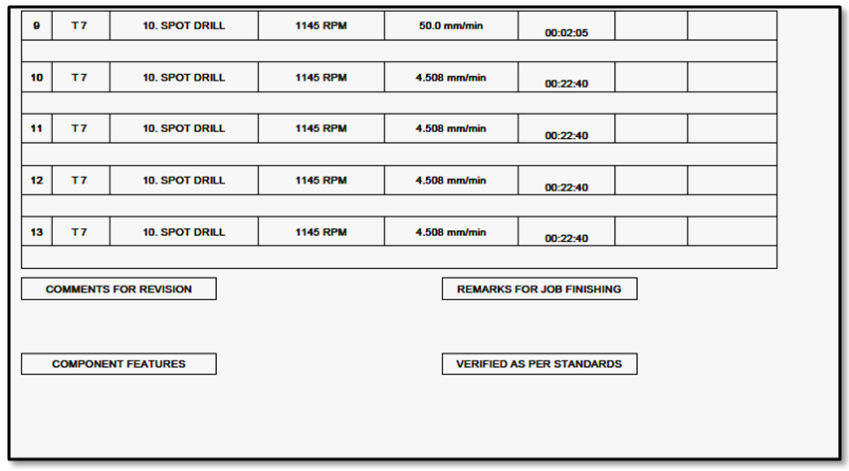

Figure 10 Setup Sheet for Customer 06

Setup Sheet 7: Parameters as Per Customer Requirement Seventh Setup sheet contains customized sheet as per requirement of company. Any additional comments or revised parameters can be set as per end user requirement. Parameters to be obtained as per client requirement, i.e.: tool number in automatic tool changer, speed, feed and estimated time for machining.

\begin{tabular}{|c|c|c|c|c|c|c|c|c|c|c|c|}
\hline \multicolumn{4}{|c|}{$\begin{array}{l}\text { ssily open all your files } \\
\text { cross devices. }\end{array}$} & \multicolumn{4}{|c|}{ CAMPROGRAM SHEET } & OATE & \multicolumn{3}{|c|}{ 12-Feb-15 } \\
\hline \multicolumn{2}{|c|}{ TYPE } & & $\begin{array}{l}\text { MASTERCAM } \\
\text { VERRFICATION }\end{array}$ & & \multicolumn{2}{|c|}{ MODEL FROM } & CAM & ATC: & MACHINE & \multicolumn{2}{|c|}{ FANUC } \\
\hline \multicolumn{2}{|c|}{ JOBNO. } & 1255 & ITEM NO. & & \multicolumn{3}{|c|}{ TOOL NO. } & & RV RUNOUT & \multicolumn{2}{|c|}{$\begin{array}{c}\text { OH } \\
\text { OVERHANG } \\
\end{array}$} \\
\hline \begin{tabular}{|l|} 
SR. \\
NO.
\end{tabular} & \multicolumn{2}{|c|}{$\begin{array}{l}\text { PROGRAM } \\
\text { NAME }\end{array}$} & CUTTER & $\mathrm{O} / \mathrm{H}$ & RPM & DOC & FEED & STOCK EST. TIM & \begin{tabular}{l|l|} 
MEE & REAL \\
TIME
\end{tabular} & PS NO. & DATE \\
\hline 1 & $T 1$ & \multicolumn{2}{|c|}{ 10. FLAT ENDMILL } & $3500 \mathrm{RPM}$ & & \multicolumn{2}{|c|}{$3.581 \mathrm{~mm} / \mathrm{min}$} & \multicolumn{2}{|l|}{$08: 17: 21$} & & \\
\hline 2 & T214 & \multicolumn{2}{|c|}{ 5. FLAT ENDMILL } & \multicolumn{2}{|l|}{3500 RPM } & \multicolumn{2}{|c|}{$500.0 \mathrm{~mm} / \mathrm{min}$} & \multicolumn{2}{|l|}{ 00:10:51 } & & \\
\hline 3 & $\mathrm{T1}$ & \multicolumn{2}{|c|}{ 10. FLAT ENDMIL } & \multicolumn{2}{|l|}{3500 RPM } & \multicolumn{2}{|c|}{$3.581 \mathrm{~mm} / \mathrm{min}$} & 08:17:21 & & & \\
\hline 4 & $\mathrm{T1}$ & \multicolumn{2}{|c|}{ 10. FAAT ENOMLL } & \multicolumn{2}{|c|}{$3500 \mathrm{RPM}$} & \multicolumn{2}{|c|}{$500.0 \mathrm{~mm} / \mathrm{min}$} & $00: 05.36$ & & & \\
\hline 5 & T7 & \multicolumn{2}{|c|}{ 10. SPOT DRILL } & $1145 \mathrm{RPM}$ & & \multicolumn{2}{|c|}{$100.0 \mathrm{~mm} / \mathrm{min}$} & 00:01:04 & & & \\
\hline$\theta$ & $T 7$ & \multicolumn{2}{|c|}{ 10. SPOT DRILL } & $1145 \mathrm{RPM}$ & & \multicolumn{2}{|c|}{$4.508 \mathrm{~mm} / \mathrm{min}$} & $00: 22: 40$ & & & \\
\hline 7 & T7 & \multicolumn{2}{|c|}{ 10. SPOT DRILL } & $1145 \mathrm{RPM}$ & & $4.508 \mathrm{~m}$ & & $00: 22: 40$ & & & \\
\hline 8 & T7 & 10.SPC & DRILL & $1145 \mathrm{RPM}$ & & $4.508 \mathrm{~m}$ & & 00:22:40 & & & \\
\hline
\end{tabular}

Figure 11 Setup Sheet for Customer 07

\section{Setup Sheet 8: Machine Wise Sheet}

Eighth setup sheet contains details about any specific operations. For instance if two three operations are carried out on one machine then while other are completed on some different machine then operation list of two machine should be different. Such any 3 process data are customized in this sheet.Parameters to be obtained as per client requirement are as follows: Combination of 3 toolpaths (roughing, semi-finishing, finishing), Company logo, date, machining time, approval format and comment space for remarks.

\begin{tabular}{|c|c|c|c|c|c|c|}
\hline 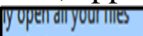 & & & & & & \\
\hline sssdevices. & TOOLDIVISION & CAMPROGR & USH & & & 20202:2015 \\
\hline TYPE & \begin{tabular}{|l|} 
MASTERCAM \\
VERFICATION
\end{tabular} & $\begin{array}{l}\text { MODEL } \\
\text { FROM }\end{array}$ & CAM & ATC: & MACHNE & FANUC \\
\hline
\end{tabular}

\begin{tabular}{|c|c|c|c|c|c|c|c|c|c|c|c|c|}
\hline iR. & \begin{tabular}{|c} 
PROGRAM \\
NAMME
\end{tabular} & NO. & CUTER & $\mathrm{OH}$ & RPP & $D O C$ & FEED & STOCK & EST.TIME & $\begin{array}{l}\text { REAL } \\
\text { TMEE }\end{array}$ & PS NO & DATE \\
\hline 1 & & 1 & 10. FLAT ENDMLLL & 800 & 3500RPM & & $\begin{array}{l}3.581 \\
\text { mm/nin }\end{array}$ & & |18:40:20 & & & \\
\hline 2 & & 214 & 5. FLAT ENDMILL & 80.0 & 3500RPM & & $\begin{array}{c}500.0 \\
\text { mm/in }\end{array}$ & & 00:10:51 & & & \\
\hline 5 & & 7 & 10. SPOT ORILL & 80.0 & 1145RPM & & $\begin{array}{l}1000.0 \\
\text { m/min }\end{array}$ & & 02:41:52 & & & \\
\hline
\end{tabular}

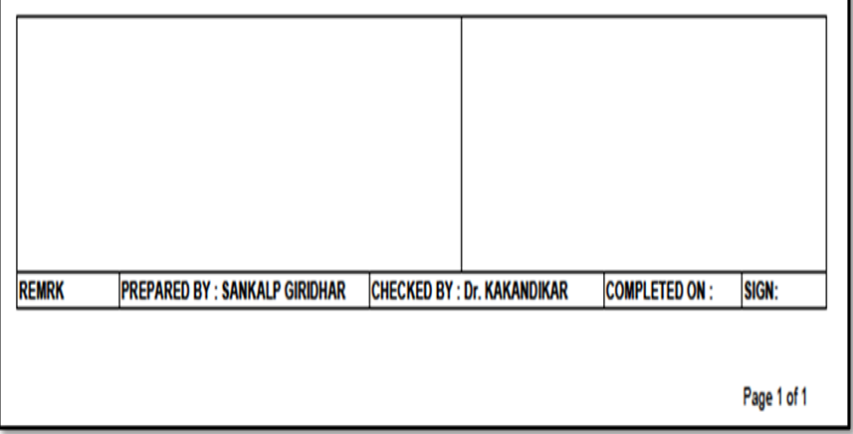

Figure 12 Setup Sheet for Customer 08

Setup Sheet 9: Final Sheet with Maximum Parameters

Ninth Setup sheet contains maximum no. of parameters that can be customized in single sheet. It also includes machine details and controller specifications. Such a setup sheet can be considered as a final revised sheet for any given component. Parameters to be obtained as per client requirement are as follows: Machine dateils, date, job number, program name, depth of cut, speed, feed, estimated time, real time, over hang, cutter name and stock remaining after each operation. 


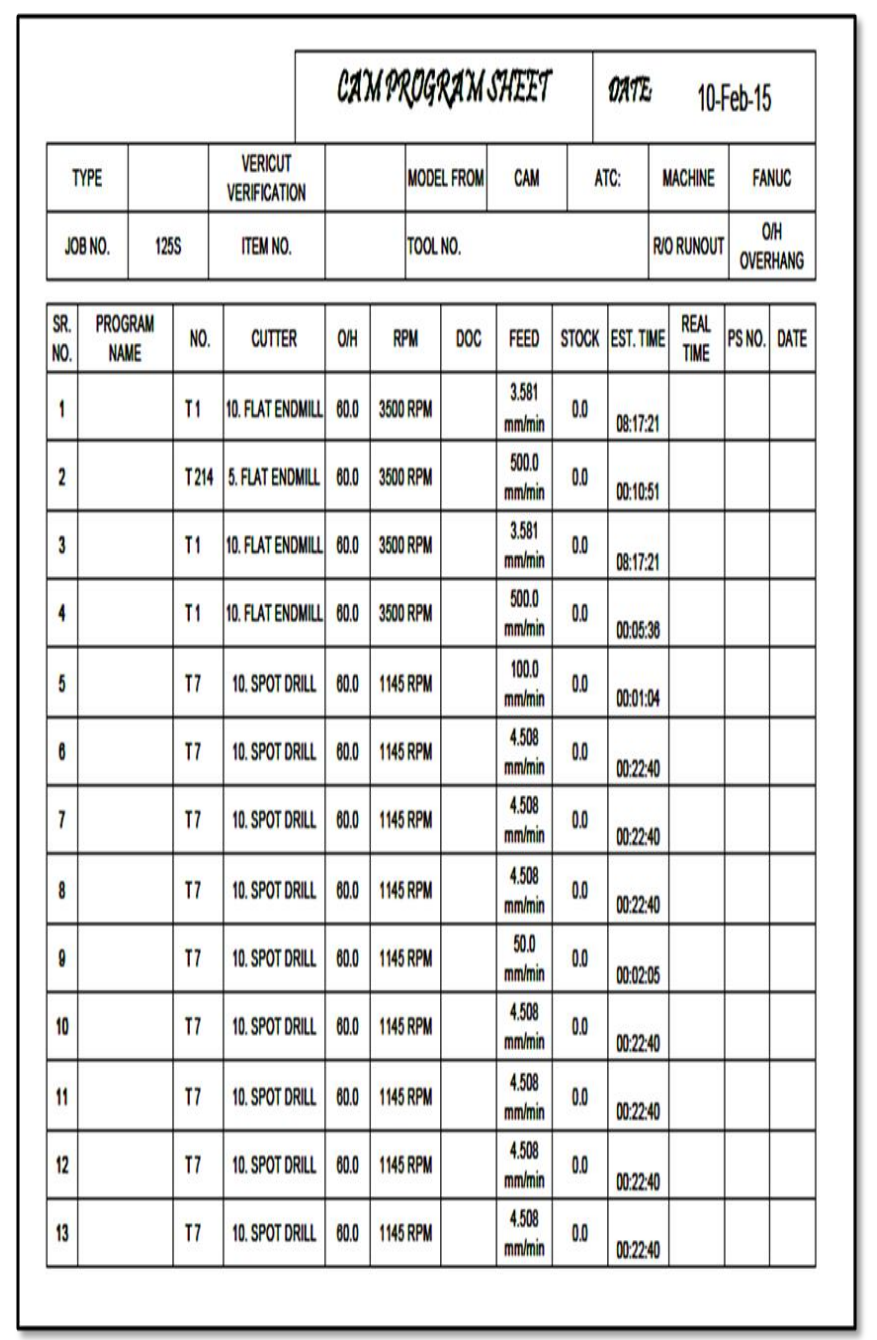

Figure 13 Setup Sheet for Customer 09

\section{CONCLUSION}

Developing organizations using the Setup sheets generated by Mastercam, facing the issue to maintaining the huge amount of bundles of sheet for all the processes, thus this can be tackled by reducing the size of these sheetsup to remarkable extent, where maximum required data with minimum storage size. Even maintaining revisions of data base is possible with optimum efforts. Customisation of such machining data will surely help all programmers to understand and perform job setting and operations. It will also benefit supervisors to check each component machining with its individual parameters in reference and benefit in improving product flow efficiency by using minimum documentation. Time required for each operation to complete will be less as customized setup sheets are available. Comparison of real time and estimated time would help in analysing proper working of processes. Accuracy is maintained as job setup and tool orientation is defined in user friendly manner.

\section{REFERENCES}

1. Gilmore Appelqvist, P., and J. M. Lehtonen (2005), Combining optimisation and simulation for steel production scheduling. Journal of Manufacturing Technology Management, Vol. 16, No. 2, pp. 197-210, ISSN: 1741-038X.

2. Gulibert D., Garavito E. (2003), Universidad Industrial de Santander, Industrial Engineering, "Modern Optimization Techniques", Bucaramanga, Colombia, pp. 64-71.
3. Hart C., Harrel C., Ghosh B. and Bowden R. (2004) "Simulation Using Promodel". United States of America: 2nd Edition. McGraw Hill, pp.7, $203-220$.

4. Chang TC, Wysk RA, Wang HP (2006) Computer-aided manufacturing, 3rd edn. Prentice Hall, Englewood Cliffs.

5. Xu HM, Mi LC, Li DB (2007) A decision logic schema of process planning using backward chaining reasoning. Int. J Adv. Manuf. Technology 38(11-12):1181-1191.

6. Xu HM, Li DB (2008) A clustering-based modelling scheme of the manufacturing resources for process planning. Int. J Adv. Manuf. Technology 38(1-2):154-162.

7. Xu HM, Li DB (2008) A meta-modelling paradigm of the manufacturing resources using mathematical logic for process planning. Int. J Adv. Manuf. Technology 36(9-10):1022-1031 \&Xu HM, Li DB (2008) Modelling of process parameter selection with mathematical logic for process planning. Robot Computer Integrated Manuf. (in press). doi:10.1016/j.rcim. 2008.03.001.

8. Tseng Fu, Jiao Su Park (2001), "Simulation Optimization Methodologies", Proceedings of the 2001 Winter Simulation Conference, pp. 93-100.

9. Kelton D., Sadowski R. and Swets N. (2010), "Simulation with ARENA", 5th Edition, McGraw Hill, New York.

10. Law A. (2007), "Statistical Analysis of Simulation Output Data: The practical State of Art", Proceedings of the 2009 Winter Simulation Conference, pp. 77-83.

11. Schutten D, Mosca R, Cassettari L, Revetria R and Gianluca M. (2005), "Simulation as Support for Production Planning in Small and Medium Enterprise: A Case Study", Proceedings of the 2005 Winter Simulation Conference, Kuhl et al (eds), pp. 2443-2448.

12. Piller R. (2006), "Verification and Validation of Simulation Models", Proceedings of the 2006 Winter Simulation Conference, pp. 162-176.

13. Schutten D., Slack N., Chambers S., Johnston R. and Betts A. (2006), "Operations and Process Management, Principles and Practices for Strategic Impact”, Prentice Hall-Pearson Education, Harlow, Essex, pp. 119-133.

14. Cam Instructor (2010), Mastercam Reference Guide Vol. 1, issue 3-4.

15. Summers \& team, October 2010, Official Dealer copy of Mastercam Focus SeriesTutorials, creating setup sheets with active designer reports Vol. 1-2-3

\section{AUTHORS PROFILE}

Dr. Vishal V. Shukla is Associate Professor, Mechanical Engineering, at

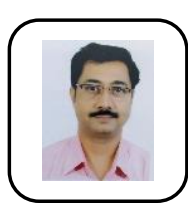
Shri Ramdeobaba College of Engineering and Management (RCOEM), Nagpur, India. He holds a Ph.D in Mechanical Engineering, awarded by Visvesvaraya National Institute of Technology (VNIT), Nagpur. He has to his credit 3 patents, a reference book and about 20 research papers. He is member of International Society of Automation, Institution of Engineers, ISHRAE, ISTE, Indian Society of biomechanics. His areas of interest/expertise are Mechanical system Design, FEM, CFD, Solar Power, Additive Manufacturing etc. He is also a consultant \& advisor for installation of Elevators \& Roof Top solar systems.

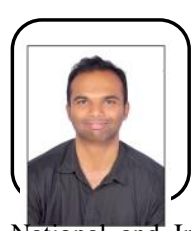

Dr. Pranil V. Sawalakhe is Assistant Professor, Mechanical Engineering, at Shri Ramdeobaba College of Engineering and Management (RCOEM), Nagpur, India. He holds a Ph.D in Mechanical Engineering, awarded by RTMNU, Nagpur also MSc in Advanced Manufacturing systems awarded by Teesside University UK. He is member of IAENG. He has published his research many Nomald and International Journals. He in the field of and Teaching from 8 Yrs.

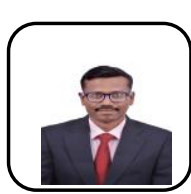

Jahier Abbas Shaaikh is a lecturer, Mechanical Engineering, Debre Tabor University, Ethiopia and pursuing PhD from K.L University. He was working in Aerospace and defense industry in operation and project management. He has 12 Yrs experience in setting up laboratories, imparting project based learning and enhancing students employability. He is in the field of Research and Teaching from 11 Yrs.

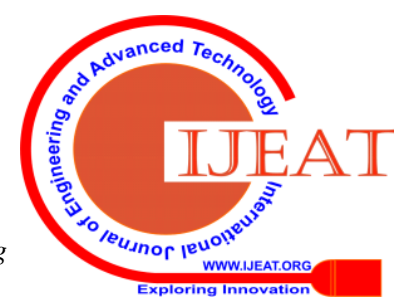


M. G. Trivedi is an Assistant Professor, Mechanical Engineering, at Shri Ramdeobaba College of Engineering and Management (RCOEM), Nagpur, India. and Pursing Ph.D. in Production Engineering, from S.G.B. Amravati University (Prof. Ram Meghe Institute of Technology and Research, Amravati. He has to his credit 2 patents, and about 8 research papers. He is member of Indian Society of Technical Education. His areas of interest/expertise are Additive Manufacturing, CAD-CAM-CAE etc.

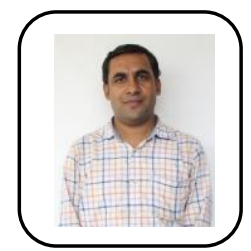

N.P. Gudadhe is an Assistant Professor, Mechanical Engineering, at Shri Ramdeobaba College of Engineering and Management (RCOEM), Nagpur, India. and Pursing Ph.D. in Mechanical Engineering, NIT, Raipur. He has to his credit 1 patent and some good amount of research papers. His areas of interest/expertise is Manufacturing. 